\title{
Numerical Analysis of Dynamic Properties of Nonlinear Rotor Systems of Aircraft Jet Engines
}

\author{
JÁN KAMENICKÝa ${ }^{\mathrm{a}}$, EDUARD MALENOVSKÝ ${ }^{\mathrm{b}, *}$ and JAROSLAV ZAPOMĚL ${ }^{\mathrm{c}}$ \\ a Brno Military Academy, Kounicova 65, PS 13, 61200 Brno, Czech Republic; ${ }^{b}$ Faculty of Mechanical Engineering, \\ Institute of Solid Mechanics, Brno. Technical University, Technická 2, 61669 Brno, Czech Republic; \\ ${ }^{\mathrm{c} O s t r a v a}$ Technical University, 17 Listopadu, 72100 Ostrava, Czech Republic
}

(Received 23 April 1998; In final form 16 December 1998)

\begin{abstract}
The paper deals with a manner of modelling and results of the calculation of dynamic properties and vibrations of the double spool aircraft turbofan engine AI-25, used in aeroplanes L-39 (Albatross). The calculations take into account the flexibilities of the engine's both coaxial rotors, their supports (including their hydrodynamic dampers), and its casing as well. Besides the short description of the engine design peculiarities and of its calculating model, there is also a short description of the used method of calculations, with focus on its peculiarities as well. Finally, some results of calculations and conclusions that follow from them are presented.

The calculating model of the engine is considered as a dynamic system that consists of two coaxial rotors, their flexible supports, and the engine casing. The model respects nonlinear elements between rotating and nonrotating parts of the engine, such as e.g., the oil squeeze damper, the labyrinth sealing, etc. The rotor system is considered as rotationally symmetric and with internal material damping. The basic calculating model is based on the finite elements method (FEM). For the more demanding nonlinear problems which would allow to respect also the flexibilities of the engine stator parts and especially their experimentally obtained data, the method of dynamic compliances was found to be more successful. It was also found that the nonlinear problems of complicated rotor systems require special algorithms of calculations to be applied.
\end{abstract}

Keywords: Rotor systems, Nonlinear vibrations, Numerical analysis, Vibrodiagnostics, Aircraft jet engines

\section{INTRODUCTION}

The reliability and the lifetime of the aircraft jet engines are closely connected with the magnitudes of their vibrations in working conditions. They depend not only on the magnitude of service disbalance of the engines' particular rotors (which can vary during the engine service), but also on the dynamic properties of the engine as a whole. Knowledge of these engine dynamic properties

*Corresponding author. Tel.: 00420541183315. Fax: 0042054118 2888. E-mail: Kamen@cs.vabo.cz. 
thus has great importance not only during the process of engine design and development but also in course of their vibrodiagnostics in the service. For the mentioned engines the coaxial arrangement of their rotors and considerable casing flexibility is typical, which is also the reason for the importance of their bound flexural whirling vibrations.

One typical representative of these engines is the aeroengine AI-25 from the military advanced trainer L-39 (Albatros) of Czechoslovak production, shown in Fig. 1. During the vibrodiagnostic service tests of this engine (and also of another similar one) it was found that reliable measuring of the engine vibrations is possible only on the engine casing, by means of accelerometers fixed at the points marked by letters $\mathrm{K}$ and $\mathrm{T}$ in Fig. 1. Our experience gained at that time is presented in Kamenický et al. (1993). Figures 2 and 3 show two typical vibration spectra of this engine obtained by means of the accelerometer located on its casing at point K (Fig. 1). Figure 2 presents the engine vibration spectra under slow change of its rotational speeds $(\mathrm{Hz})$, while Fig. 3 represents a spectrum at the instantaneous time period $t=176 \mathrm{~s}$.

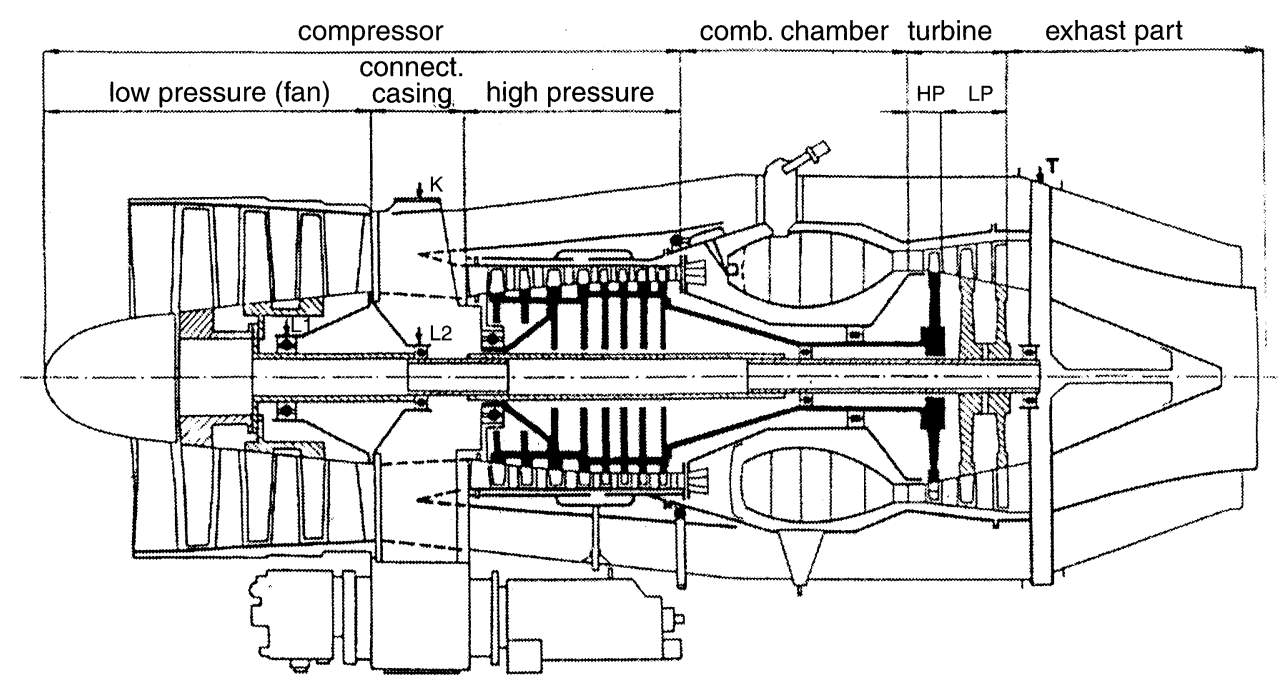

FIGURE 1 Simplified scheme of the engine AI-25.

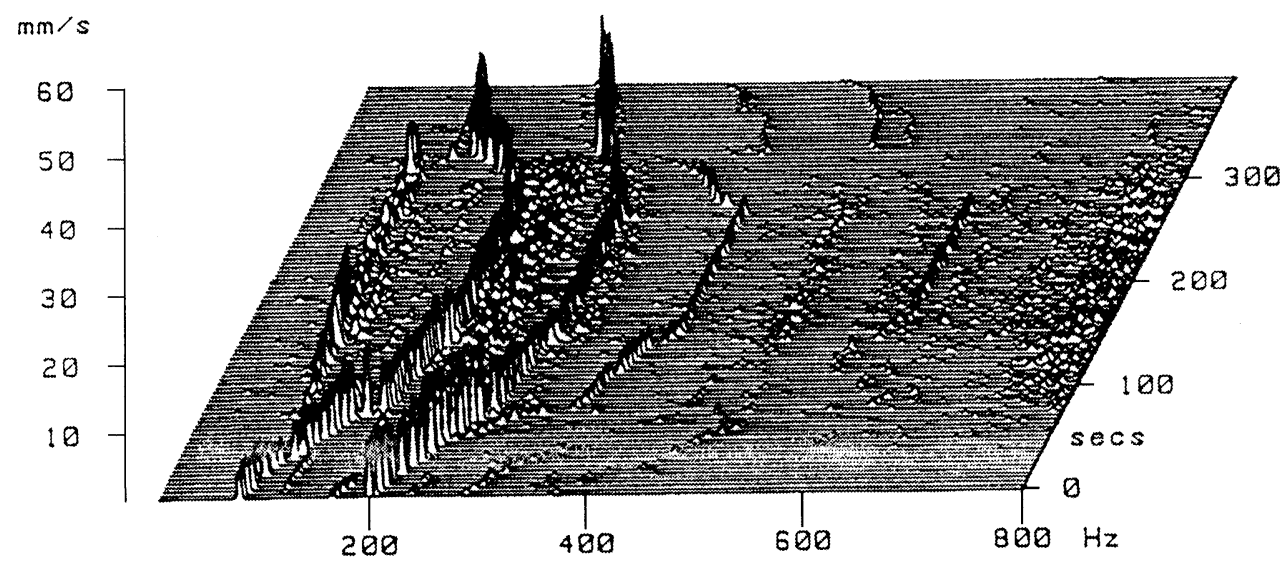

FIGURE 2 Time dependence of the engine spectra. 


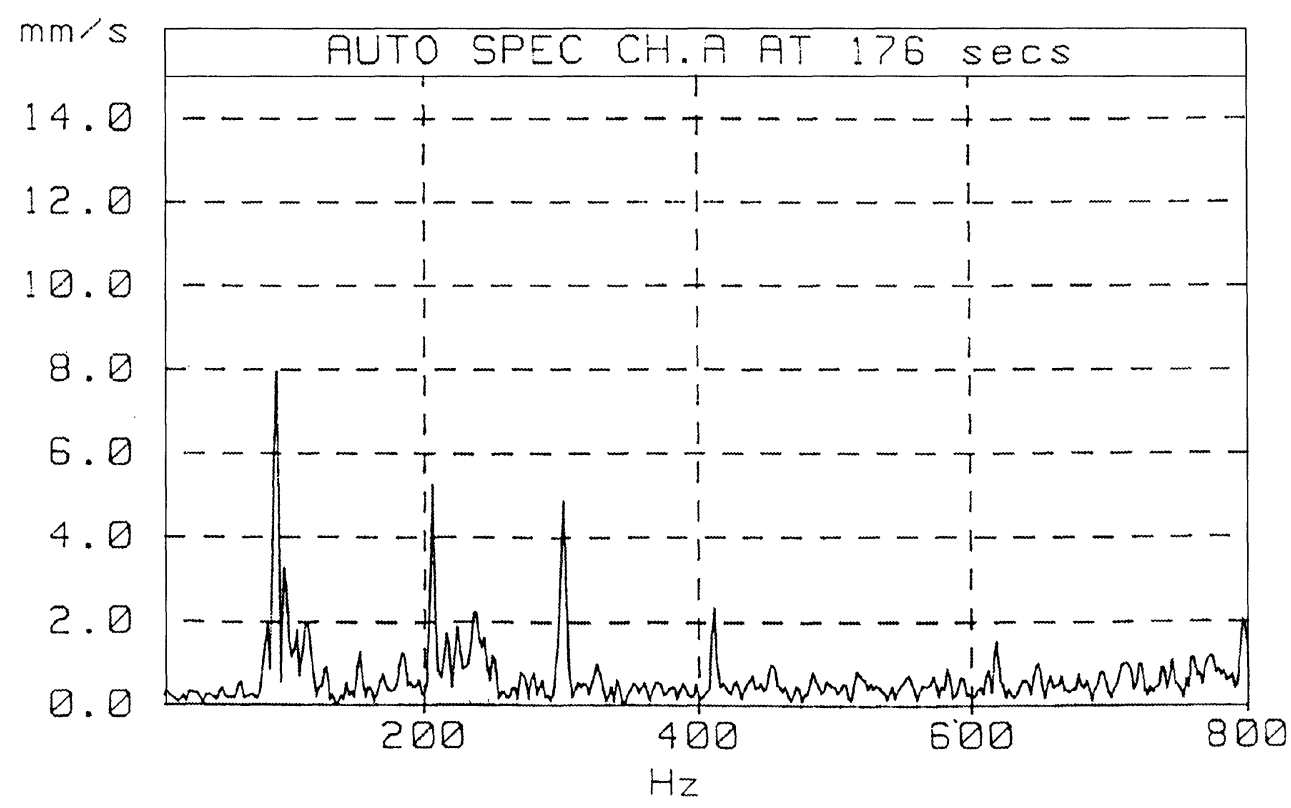

FIGURE 3 Instantaneous vibration spectra of the engine at $t=176 \mathrm{~s}$ (see Fig. 2).

The vibration components at frequencies $f_{\mathrm{L} 1} \approx 210 \mathrm{~Hz}$ and $f_{\mathrm{L} 2} \approx 420 \mathrm{~Hz}$ here correspond to the first (subscript 1) and second (subscript 2) harmonics of the low pressure rotor (subscript $\mathrm{L}$ ) and $f_{\mathrm{H} 1} \approx 315 \mathrm{~Hz}$ and $f_{\mathrm{H} 2} \approx 630 \mathrm{~Hz}$ are the same harmonics of the high pressure rotor (subscript $\mathrm{H}$ ). The biggest amplitude of the spectra in Fig. 3 is evidently the component with frequency $f_{\mathrm{L} X} \approx 0.5$. $f_{\mathrm{L} 1} \leq(0.45-0.50), f_{\mathrm{L} 1} \approx 95 \mathrm{~Hz}$. Some engines do not have this vibration component at all, another group of engines have the amplitude of this component (roughly) ten times greater than those ones at frequencies $f_{\mathrm{L} 1}$ and $f_{\mathrm{H} 1}$. Also the amplitudes of frequency components of $f_{\mathrm{L} 1}$ and $f_{\mathrm{H} 1}$ differed for different groups of engines in their magnitudes. It is obvious that the explanation of these peculiarities of different groups of the same engine design can be offered only by a mathematical modelling of this engine bound flexural vibration that allows imitation of its various service excitations.

This paper describes the method used and presents some partial (but typical) results from the vibration modelling of the above mentioned engine. It also summarises our experience gained during the process of the problem solution.

\section{DESCRIPTION OF THE ENGINE AND ITS CALCULATING MODEL}

The simplified longitudinal cross section of the engine AI-25 and its calculating model are presented in Figs. 1 and 4. The by-pass ratio of this double spool aircraft engine is 2.0 and its take off thrust is $17 \mathrm{kN}$. The length and face diameter at the engine inlet (see Fig. 1) are 2.1 and $0.60 \mathrm{~m}$, and its total mass (including accessories) is approximately $400 \mathrm{~kg}$. The operational ranges of high pressure (HP) and low pressure (LP) rotors of the engine are $n_{\mathrm{H}}=$ 10000-18000 RPM and $n_{\mathrm{L}}=7000-12000 \mathrm{RPM}$. The distances of the fan and HP compressor own bearings are 0.237 and $0.670 \mathrm{~m}$. Their front ball bearings (of external diameter $120 \mathrm{~mm}$ ) are equipped with hydrodynamic, so-called squeeze film dampers (SFD). Further main bearings of the engine rotors are roller ones and without SFD.

From the calculating model of the engine (Fig. 4) it is evident that the number of the calculating nodes of the HP and LP rotors are 12 and 15, and that of the engine casing is 21 . In the case of the linear calculating model (i.e. both rotors without SFD), the following stiffnesses of the respective rotor 


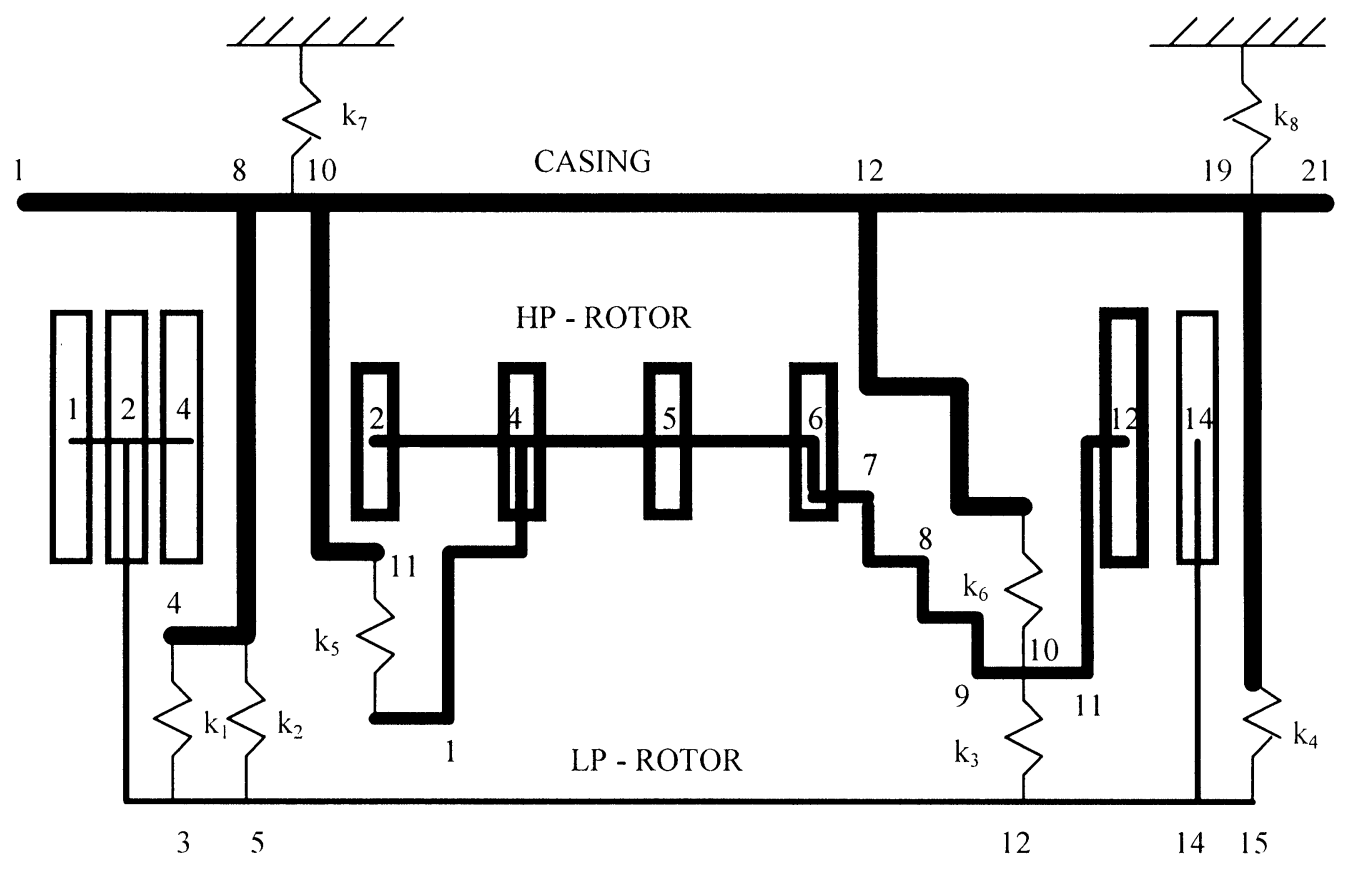

FIGURE 4 Calculating model of the engine AI-25.

supports were assumed: $k_{1}=3.61 \cdot 10^{7} \mathrm{~N} / \mathrm{m}$ and $\left.k_{5}=9.615 \cdot 10^{7} \mathrm{~N} / \mathrm{m}\right)$, together with local dampings $b_{1}=b_{5}=1 \cdot 10^{3} \mathrm{~N} \mathrm{~s} / \mathrm{m}$ and with the parameter of proportional damping $\beta=1 \cdot 10^{-5}$. In the case of the nonlinear model, the properties of the SFD were calculated using the method described further. The internal excitation of the HP rotor was considered at point 12 of $5 \cdot 10^{-4} \mathrm{~kg} \mathrm{~m}$ and that of the LP rotor at points 1 and 14 of $1 \cdot 10^{-3} \mathrm{~kg} \mathrm{~m}$.

\section{THE USED METHOD OF CALCULATION}

The calculations were performed by the Program System of Rotordynamics of the Mechanical Faculty of Brno Technical University consisting of various calculating procedures presented by Malenovský and Zapoměl (1994, 1995), Malenovský and Kamenický (1995), Zapoměl and Malenovský (1993, 1994, 1996). They are based on the finite element method (FEM) and on the method of dynamic compliances (MDC) that are known, e.g. from Vance (1990), Bishop et al. (1965), Lalanne and Ferraris (1990), Krämer (1993), ElShafei (1991), El-Shafei and Eranki (1996). The specific procedures in this Program System of Rotordynamics are divided into the linear and nonlinear ones and further, according to the needs, to the calculation of eigenvalues (including their respective vectors) and to the calculation of responses in the case of forced vibration.

The possibilities and ways of taking into account the nonlinear features of SFDs of different kinds and design variants are described in Vance (1990), El-Shafei (1991), El-Shafei and Eranki (1996). Our Program System of Rotordynamics is for the time being based only on the method described by ElShafei (1991), El-Shafei and Eranki (1996). For the solution of the systems of nonlinear equations the Aitken or Newton-Raphson methods were used.

For the calculation of the eigenvalues of the engine and their respective deflection curves, using 
MDC, following equation was used:

$$
\left[\begin{array}{cc}
-G_{11}^{\mathrm{L}}-G_{11}^{\mathrm{H}}-G^{\mathrm{LH}} & -G_{12}^{\mathrm{L}} \\
-G_{21}^{\mathrm{L}} & -G_{22}^{\mathrm{L}}-G_{11}^{\mathrm{C}}-G^{\mathrm{LC}} \\
+G_{21}^{\mathrm{H}} & -G_{21}^{\mathrm{C}}
\end{array}\right.
$$

In this equation $G_{i j}$ are matrices of dynamic compliances of the HP and LP rotors (abbreviations $\mathrm{H}$ and $\mathrm{L}$ ), or of the engine casing (abbreviation $\mathrm{C}$ ), where the subscripts 1 or 2 mark the submatrices in the total matrices of isolated engine parts $(\mathrm{H}, \mathrm{L}, \mathrm{C})$, which are utilised for the derivation
The solution of the engine forced vibration was based on the assumption that the dominant

$\left.\begin{array}{c}+G_{12}^{\mathrm{H}} \\ -G_{12}^{\mathrm{C}} \\ -G_{22}^{\mathrm{H}}-G_{22}^{\mathrm{C}}-G^{\mathrm{HC}}\end{array}\right]\left[\begin{array}{c}Q^{\mathrm{LH}} \\ Q^{\mathrm{LC}} \\ Q^{\mathrm{HC}}\end{array}\right]=\left[\begin{array}{l}0 \\ 0 \\ 0\end{array}\right]$.

excitation is caused by the internal disbalance of the engine rotors. Besides that it was assumed that the elliptical trajectories of the centres of the shaft around their equilibrium states are even for the nonisotropic rotor supports approximately circular.

$$
\left.\begin{array}{cc}
+G_{13}^{\mathrm{L}} & 0 \\
+G_{23}^{\mathrm{L}} & 0 \\
+G_{33}^{\mathrm{L}} & 0 \\
0 & +G_{13}^{\mathrm{H}} \\
0 & +G_{23}^{\mathrm{H}} \\
0 & +G_{33}^{\mathrm{H}} \\
-G_{11}^{\mathrm{C}} & -G_{12}^{\mathrm{C}} \\
-G_{21}^{\mathrm{C}} & -G_{22}^{\mathrm{C}} \\
0 & 0 \\
-G^{\mathrm{LC}} & 0 \\
0 & -G^{\mathrm{HC}}
\end{array}\right]\left[\begin{array}{c}
q^{\mathrm{L}} \\
q^{\mathrm{LH}} \\
q^{\mathrm{LC}} \\
q^{\mathrm{H}} \\
q^{\mathrm{HL}} \\
q^{\mathrm{HC}} \\
q^{\mathrm{CL}} \\
q^{\mathrm{CH}} \\
Q^{\mathrm{LH}} \\
Q^{\mathrm{LC}} \\
Q^{\mathrm{HC}}
\end{array}\right]=\left[\begin{array}{c}
q_{11}^{\mathrm{L}} \\
q_{21}^{\mathrm{L}} \\
q_{31}^{\mathrm{L}} \\
q_{11}^{\mathrm{H}} \\
q_{21}^{\mathrm{H}} \\
q_{31}^{\mathrm{H}} \\
0 \\
0 \\
0 \\
0 \\
0
\end{array}\right] .
$$

of the final matrix. Their order is given by the number of bonds between the individual subsystems $(\mathrm{H}, \mathrm{L}, \mathrm{C})$ of the engine.

The eigenvalues of the engine (which are complex ones) can be determined from the condition of the nontrivial solution of Eq. (1), i.e. from the condition that its determinant equals zero. Respecting the nonlinear properties of the bounding elements of the engine, e.g. their SFD, requires the knowledge of the displacement, velocity and acceleration at each of the nodes of the engine system. These kinematic magnitudes have been determined by means of the forced vibration procedure with respect to the respective rotational speed. The values obtained in such a way were then used as the starting magnitudes for finding the engine eigenvalues.
In accordance with the MDC for the forced vibration of our engine model (Fig. 4) Eq. (2) is true. In this equation $Q$ and $q$ are the force and the displacement, $E$ is the unit matrix, and $G_{i j}$ are similar matrices as in Eq. (1), but in this case their order is higher. Their order is specifically higher by the number of places (nodes) where the force of internal disbalance is applied and by the number of places (nodes) where the knowledge of the response of the system is required.

The simplified notation of Eq. (2) can be as follows:

$$
G q=Q,
$$

where $G$ is the matrix of the system, $q$ is the vector of unknown magnitudes, and $Q$ represents the right 


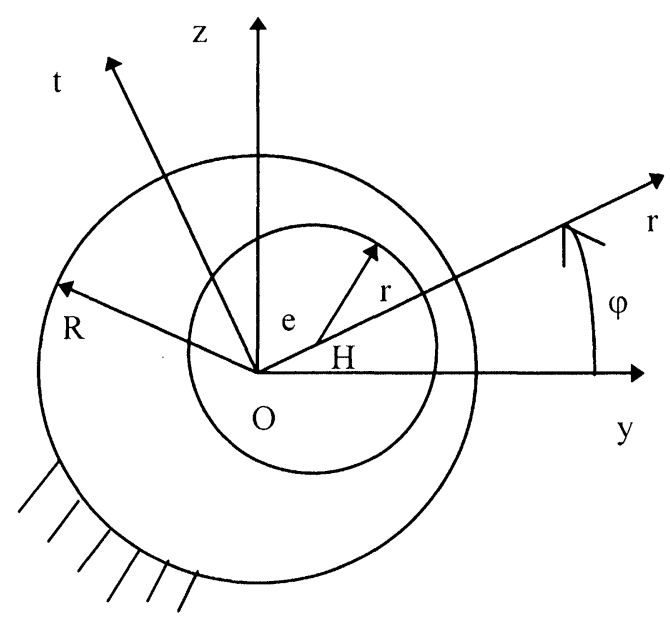

$\mathrm{O}_{\mathrm{yz}}$ - fixed co-ordinate system

$\mathrm{O}_{\mathrm{rt}}$ - rotating co-ordinate system

$\mathrm{H}$ - centre of the shaft

FIGURE 5 The relative location of the shaft and the stator.

side vector of the system of algebraic equations, which is known. The order of the matrix $G$ is given by the sum of six times total number of all bonds in the engine system plus two times the number of points (nodes) where the knowledge of the system response is required.

The starting equation for the determination of the additional forces of the SFD at the point of its location is the well-known Reynolds equation. In our case the additional damping and inertial effects of the SFD were determined (for the stable forced vibration) by the use of relations of El-Shafei (1991), El-Shafei and Eranki (1996).

For the calculation of the radial (subscript $r$ ) and tangential (subscript $t$ ) forces $(F)$ of damping and inertia, in accordance with Fig. 5, for the SFD with cavitation (i.e. with $\pi$-film), the next equation was used:

$\left[\begin{array}{l}F_{\mathrm{r}} \\ F_{\mathrm{t}}\end{array}\right]=-\left[\begin{array}{ll}b_{\mathrm{rr}} & b_{\mathrm{rt}} \\ b_{\mathrm{tr}} & b_{\mathrm{tt}}\end{array}\right]\left[\begin{array}{l}v_{\mathrm{r}} \\ v_{\mathrm{t}}\end{array}\right]-\left[\begin{array}{ll}m_{\mathrm{rr}} & m_{\mathrm{rt}} \\ m_{\mathrm{tr}} & m_{\mathrm{tt}}\end{array}\right]\left[\begin{array}{l}a_{\mathrm{r}} \\ a_{\mathrm{t}}\end{array}\right]$

Here $b$ represents the damping coefficients bound with velocity ( $v)$ and $m$ are masses bound with acceleration (a). Assuming that the elliptical trajectories are close enough to the circular ones (when the velocities and accelerations in radial and tangential directions are $v_{\mathrm{t}}=\varepsilon \dot{\varphi}, v_{\mathrm{r}}=0, a_{\mathrm{t}}=0$, $a_{\mathrm{r}}=-\varepsilon \dot{\varphi}^{2}$, in accordance with notation in Fig. 5 for the expressions of the coefficients $b$ and masses $m$, the Eqs. (5) and (6) are true.

The $\rho$ and $\eta$ in these relations are the oil density and dynamic viscosity. In the case of the SFD without cavitation, the coefficient $m_{\mathrm{rr}}$ is two times greater and the coefficient $m_{\mathrm{tt}}$ equals zero. In the general case of the SFD the relations for the determination of forces in the fixed co-ordinate system are more complex. Even far more complex would be the relations for the stiffness, damping and mass matrices, which could be obtained by the use of the respective partial derivations. For this reason it is more suitable to perform derivations numerically,

$$
\begin{aligned}
& b_{\mathrm{rr}}=\frac{\eta R^{3} L}{\delta^{3}} \frac{6 \pi}{\left(1-\varepsilon^{2}\right)^{3 / 2}}, \\
& b_{\mathrm{tt}}=\frac{\eta R^{3} L}{\delta^{3}} \frac{12 \pi}{\left(2+\varepsilon^{2}\right)\left(1-\varepsilon^{2}\right)^{1 / 2}}, \\
& b_{\mathrm{rt}}=0, b_{\mathrm{tr}}=0,
\end{aligned}
$$

$$
\begin{aligned}
& m_{\mathrm{tt}}=\frac{\rho R^{3} L}{\delta} \frac{12}{10} \frac{2 \pi}{\left(2+\varepsilon^{2}\right)^{2}}\left[6-\frac{\left(10-\varepsilon^{2}\right)\left(1-\varepsilon^{2}\right)^{1 / 2}}{\left(2+\varepsilon^{2}\right)}\right], \\
& m_{\mathrm{rr}}=\frac{\rho R^{3} L}{\delta}\left(m_{1}+m_{2}+m_{3}\right), \\
& m_{1}=-\frac{\left(3 \varepsilon /\left(2+\varepsilon^{2}\right)-1\right)^{3}}{\left(1-\varepsilon^{2}\right)}+\frac{\left(3 \varepsilon /\left(2+\varepsilon^{2}\right)+1\right)^{3}}{\left(1+\varepsilon^{2}\right)}
\end{aligned}
$$


$m_{2}=\frac{3}{5}\left[\frac{\left(3 \varepsilon /\left(2+\varepsilon^{2}\right)-1\right)^{2}}{(1-\varepsilon)}-\frac{\left(3 \varepsilon /\left(2+\varepsilon^{2}\right)+1\right)^{2}}{(1+\varepsilon)}\right]$, $m_{3}=\frac{12}{10} \frac{\varepsilon\left(8+\varepsilon^{2}\right)}{\left(2+\varepsilon^{2}\right)^{2}}, \quad m_{\mathrm{rt}}=m_{\mathrm{tr}}=0$.

\section{SOME CALCULATION RESULTS}

Our calculations were directed at first on the eigenvalues of the engine system and the respective deflection curves of its elements (i.e. of its rotors and casing). Subsequently, the problem of the stable forced vibration of the engine, caused by an internal disbalance of any point of both rotors and at any of their response points, was solved. Besides the linear problem (solved by Malenovský and Kamenický, 1995), when only the flexible massless spring supports with stiffnesses $k_{1}$ and $k_{5}$ (see Fig. 4) were supposed instead of the SFD, also the nonlinear problem with the SFD (cavitating and long from the p.o.v. of boundary conditions) was solved. The basic calculating data of these SFDs and of the oil used were following: $R=0.06 \mathrm{~m}$, $L=0.018 \mathrm{~m}, \quad \delta=0.1-0.5 \mathrm{~mm}, \eta=0.0422 \mathrm{~Pa}$ and $\rho=885 \mathrm{~kg} / \mathrm{m}^{3}$.

The analysis of the engine natural frequencies was done in the engine operational range of speeds, i.e. for the HP rotor in the range of 0 $300 \mathrm{~Hz}=0-18000 \mathrm{RPM}$ and for the LP rotor in the range of $0-200 \mathrm{~Hz}=0-12000 \mathrm{RPM}$. The slip of RPM between both rotors of the engine was simplified by the assumption of linearity, according to the relation: $n_{\mathrm{L}}=2 \cdot n_{\mathrm{H}} / 3$. First of all, the wellknown Campbell diagrams of the engine, i.e. its natural frequencies (for both the forward and the backward precession motions of its rotors) were calculated for the different rotational speeds of both rotors. These diagrams (for both the linear and nonlinear problems) we do not specify here because they are presented in a much more complex form further (see Figs. 6 and 7).

The results of the analysis of the forced vibration of the engine, caused by the internal disbalance of its rotors, are in Malenovský and Kamenický (1995). Here, i.e. in Figs. 8 and 9, we give only two examples presenting two similar amplitudefrequency (AF) relationships of the HP rotor displacement at its node 8 (see Fig. 4). They present the engine response at this node caused by its disbalance excitations of magnitudes $5 \cdot 10^{-4} \mathrm{~kg} \mathrm{~m}$ at the node 12 of the HP rotor and of the $1 \cdot 10^{-3} \mathrm{Kg} \mathrm{m}$ at the nodes 1 and 14 of the LP rotor. The relationship in Fig. 8 corresponds to the case of rotor supports without the SFD and in Fig. 9 with the SFD for the radial clearance $\delta=0.1 \mathrm{~mm}$.

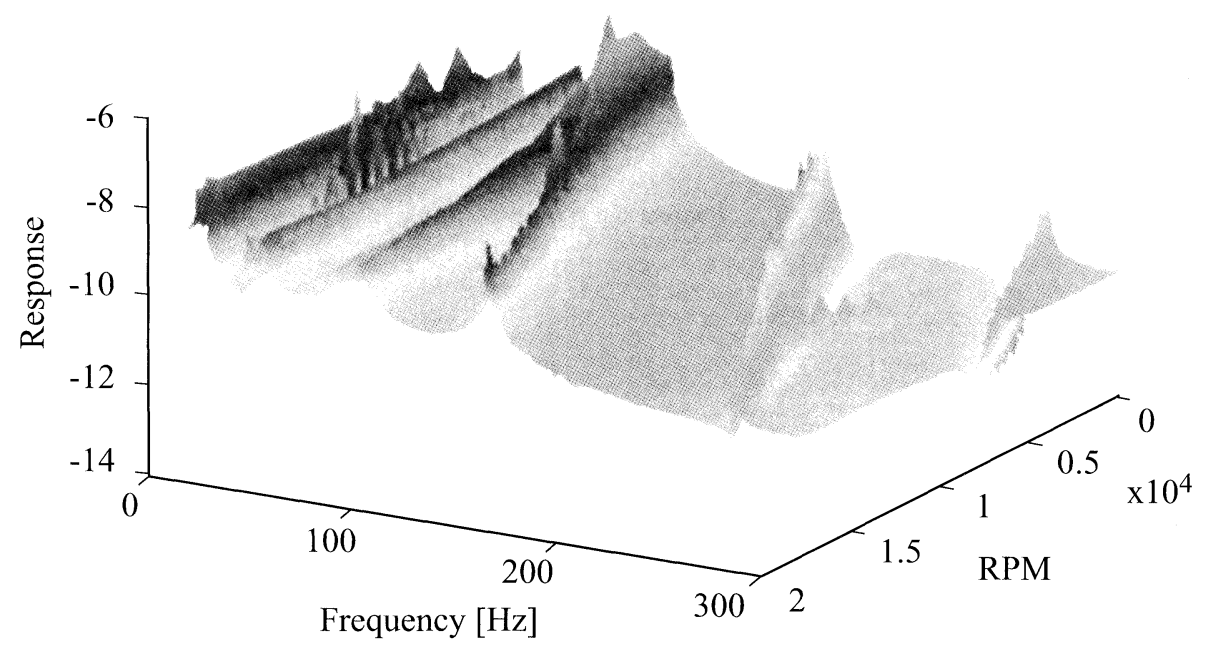

FIGURE 6 The engine 3D-response diagram at node $8 \mathrm{HP}$ rotor (linear model). 


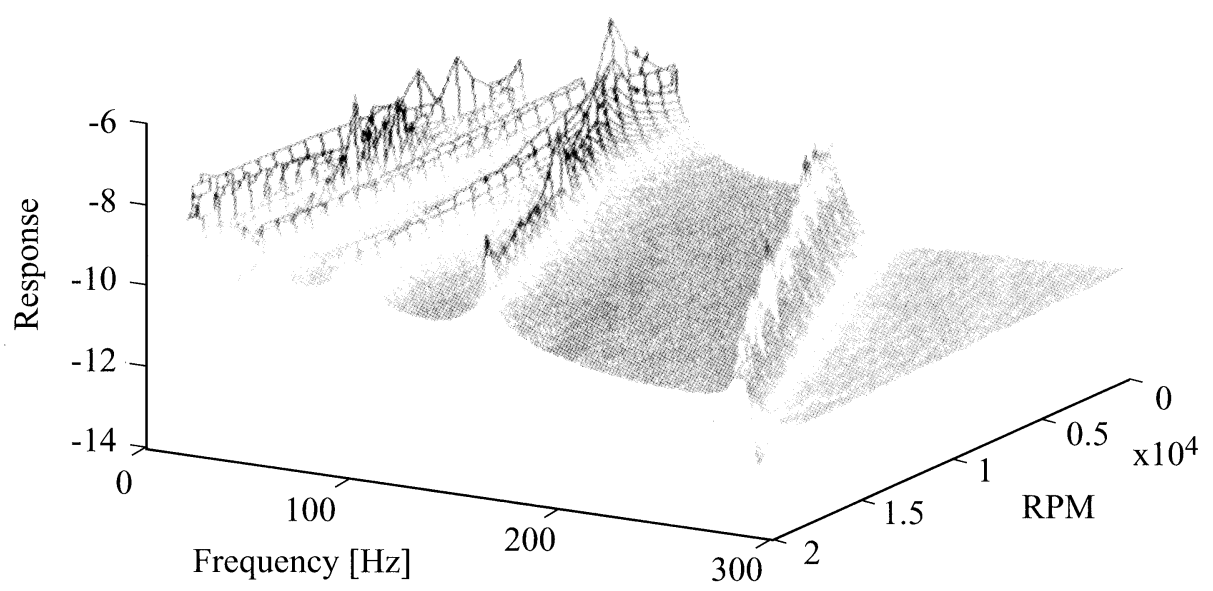

FIGURE 7 The engine 3D-response diagram at node $8 \mathrm{HP}$ rotor (nonlinear model).

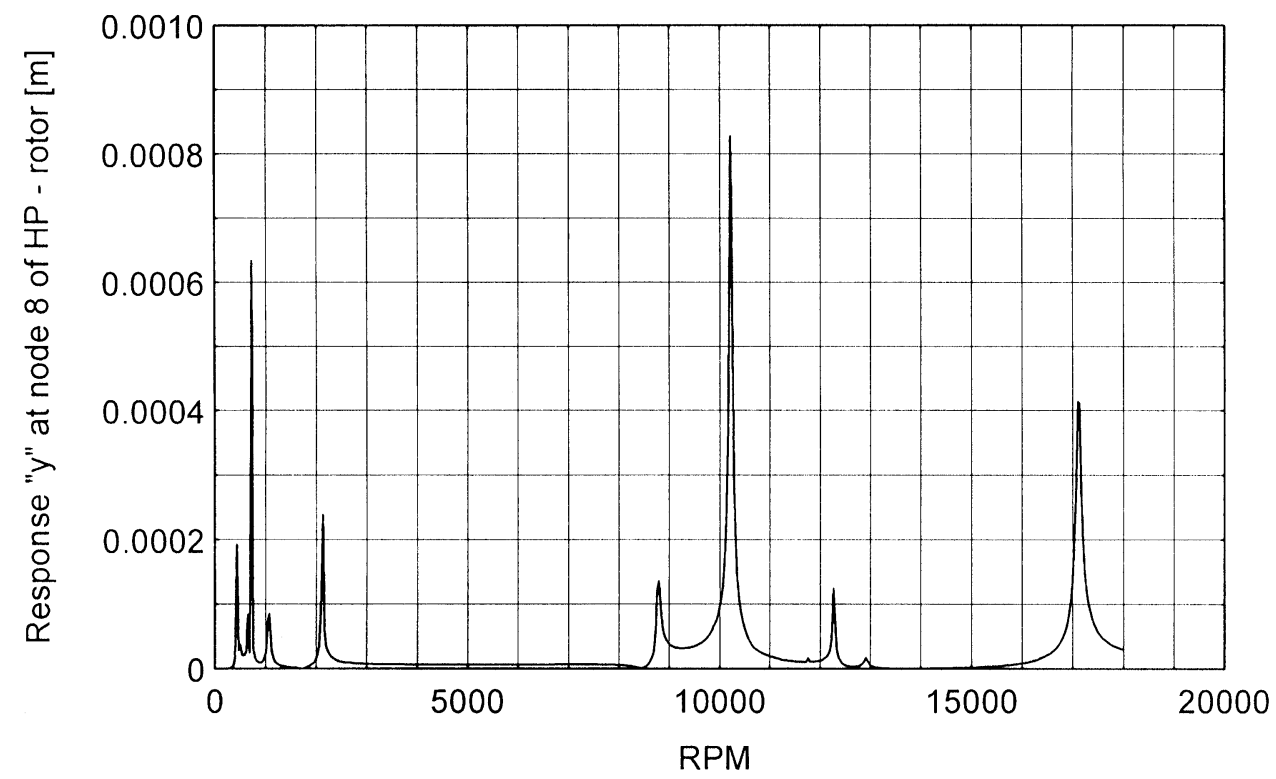

FIGURE 8 Linear model amplitude-frequency response.

From the comparison of the displacement amplitudes in both these figures it can be seen that in the case with the SFD the amplitudes are lower.

Another important result of our calculations was the determination of the deflection curves of both the engine rotors for the chosen cases of their resonance vibrations. In Figs. 10 and 11 there are two examples of them. Figure 10 corresponds to the case of rotor supports without the SFD and Fig. 11 to the case with the SFD. The respective rotational speeds of the HP rotor are $n_{\mathrm{H}}=$ $10208 \mathrm{RPM}$ in the first case and $n_{\mathrm{H}}=10786 \mathrm{RPM}$ in the second case. The location of the engine response and also the conditions of its excitation are the same in both the cases as mentioned above for Figs. 8 and 9. 


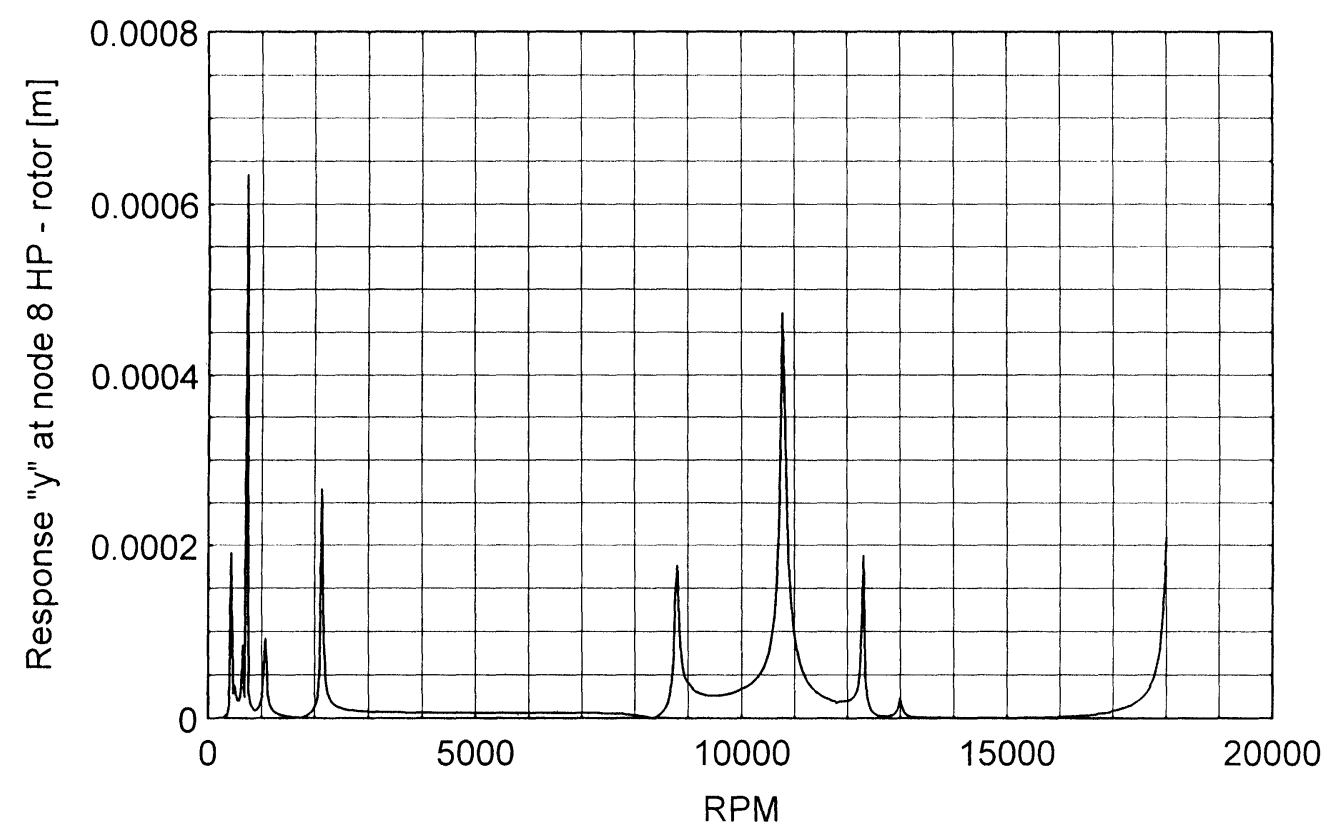

FIGURE 9 Nonlinear model amplitude-frequency response.

$\mathrm{n}_{\mathrm{H}}=10208.41 / \mathrm{min}, \mathrm{n}_{\mathrm{L}}=6805.61 / \mathrm{min}$

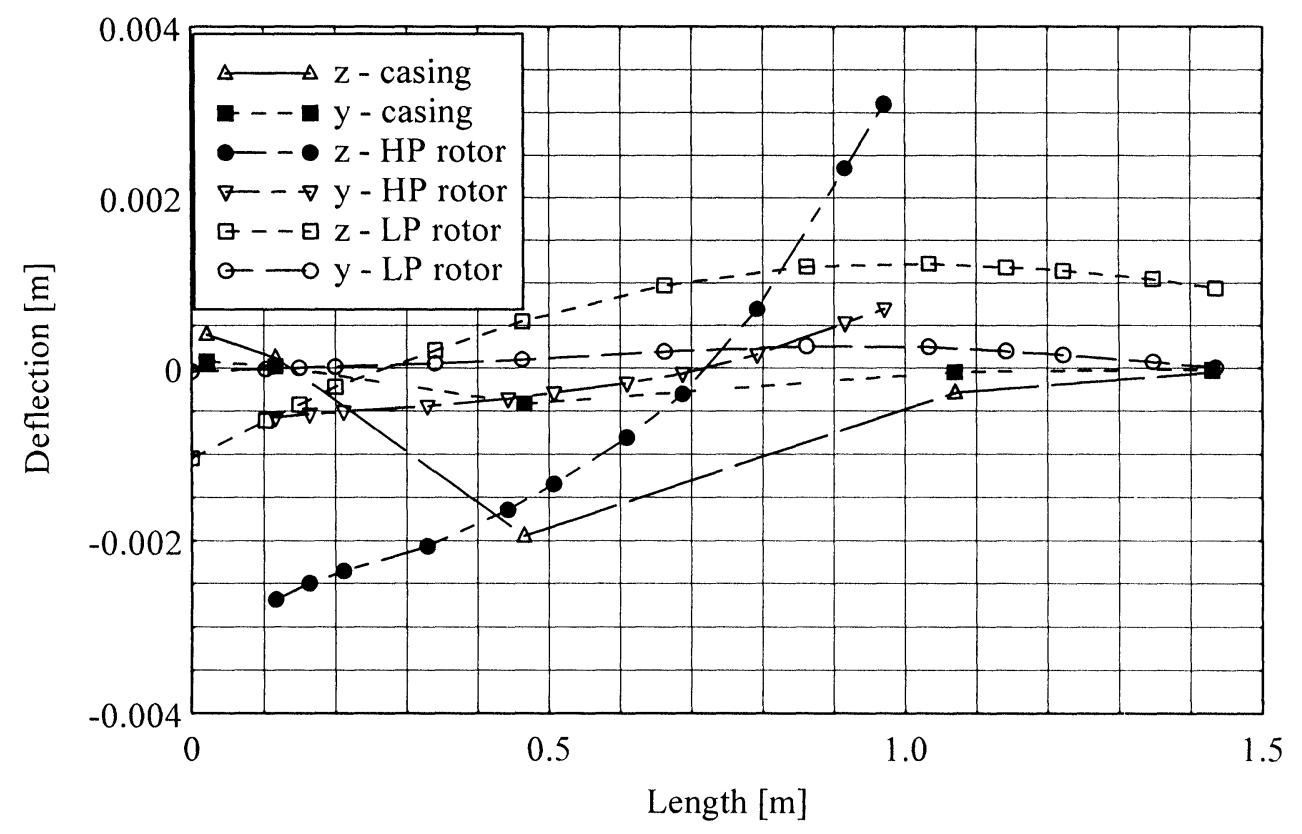

FIGURE 10 Deflection curves of linear model. 
$\mathrm{n}_{\mathrm{H}}=10785.61 / \mathrm{min}, \mathrm{n}_{\mathrm{L}}=7190.41 / \mathrm{min}$

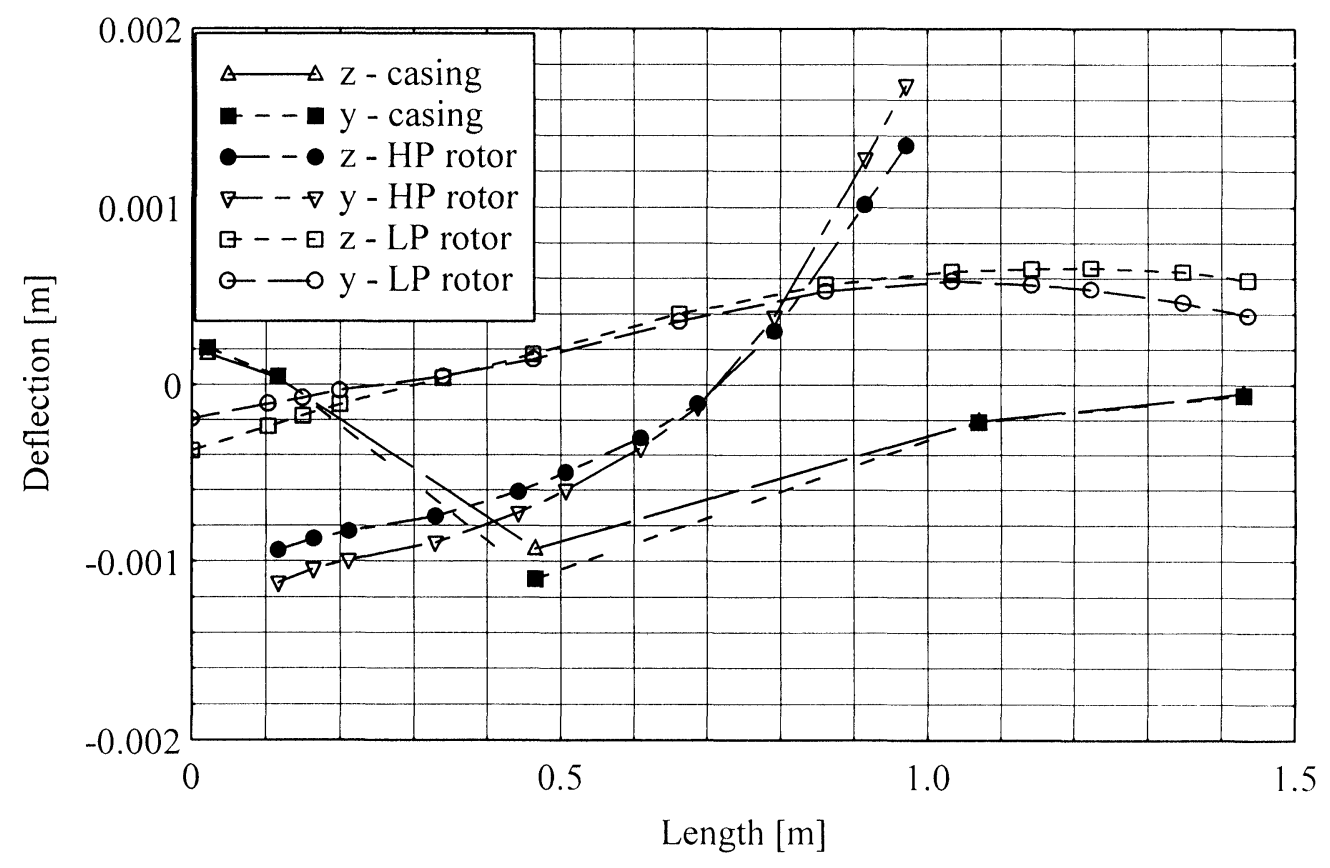

FIGURE 11 Deflection curves of nonlinear model.

\section{CONCLUSION}

The above presented results make it clear that our Program System of Rotordynamics and the calculation modelling of the bound flexural vibration of the engine AI-25 offer realistic results concerning the dynamic properties and the behaviour of the engine as a whole, as well as in regard to the behaviour of its elements. From the point of view of the service vibrodiagnostics of such engines the application of this method allows to minimise the number of used accelerometers and their easy replacement due to their location on the engine casing only.

The combination of the two calculating methods (i.e. FEM and MDC) within our Program System of Rotordynamics allows to take into account (during the calculations) more exact experimentally obtained data describing the dynamic properties of some more complex elements of the engine, e.g. their casings.
In our future work we want to direct our attention to the better adjustment of the results of the calculations to experiments. We also want to extend the possible variants of calculation of different kinds of hydrodynamic dampers and the utilisation of methods of modal analysis within our Program System of Rotordynamics. Another of our aims is the axonometric presentation of the mutual deflections of the individual parts of the engine (e.g. its coaxial rotors and casing) and the animation of their motions.

The modal method is more suitable for determination of the response at transient vibration i.e. for calculating simulations. The equation for determination of the transient vibration of the system with two coaxial shafts, stator and bounding elements is similar as in Eq. (2). On the right side there are the responses of free subsystems and the convolutory integrals. Instead of matrices of dynamic compliances there are the modal matrices. During the calculation it is necessary to analyse at first the 
free parts and the solution of the whole system can follow after that. For the solution of the nonlinear equations the Newton-Raphson method can be used. Using this model it is possible to simulate a transient of the engine at its constant RPM (e.g. simulation of a blade loss) or to simulate a transient event of the engine at its variable RPM (e.g. simulation of an engine run through its resonance state).

\section{Acknowledgements}

These studies were supported by the Grant Agency of Czech Republic with the project 101/96/0781 and 102/96/0183.

\section{NOMENCLATURE}

a Acceleration

$b \quad$ Damping coefficient

$e \quad$ Displacement of the shaft

$f$ Frequency

$F$ Force

$G \quad$ Matrix of dynamic compliances

$k \quad$ Stiffness

$L \quad$ Length of the SFD

$m$ Mass

$n \quad \mathrm{RPM}$

$q$ Displacement

$Q$ Force vector

$r \quad$ Radius of the shaft

$R$ External radius of the damper

$v$ Velocity

$\eta \quad$ Dynamic viscosity of oil

$\delta \quad$ Radial clearance $(\delta=R-r)$

$\rho \quad$ Density of oil

$\varepsilon \quad$ Relative displacement $(\varepsilon=e / \delta)$

$\varphi$ Angle between fixed and rotating co-ordinate system
Abbreviations
L, LP Low pressure rotor
H, HP High pressure rotor
FEM Finite element method
MDC Method of dynamic compliance
SFD Squeeze film damper
C Casing (of the engine)

\section{References}

Bishop, R.E.D., Gladwell, G.M.L. and Michaelson, S. (1965) The Matrix Analysis of Vibration, Cambridge University Press.

El-Shafei, A. (1991) Unbalance response of a Jeffcott rotor incorporating long squeeze film dampers. Transactions of the Vibration and Acoustics, January, Vol. 113, pp. 85-94.

El-Shafei, A.R. and Eranki, V. (1996) Dynamic force coefficients of short and long squeeze film dampers executing elliptic orbits, C432/127 IMechE, pp. 597-604, Conference "State of the Art in Numerical Analysis", University of York, UK.

Kamenický, J., Dolejší, B., Biloš, J., Labaj, J. and Chrápková, A. (1993) Ground vibrodiagnostics of jet engines, Proceedings of AIRDIAG 93', Warsaw, Poland.

Krämer, E. (1993) Dynamics of Rotors and Foundations, SpringerVerlag, Berlin.

Lalanne, M. and Ferraris, G. (1990) Rotordynamics Prediction in Engineering, John Wiley and Sons, Chichester, New York, Brisbane, Toronto, Singapore.

Malenovský, E. and Zapomèl, J. (1995) The selective problems of calculating modelling of dynamics of nonlinear rotor systems. Final Report of Granted Research GAČR No. 101/93/0297, TU Brno (in Czech).

Malenovský, E. and Kamenický, J. (1995) The calculating modelling of vibration of double spool aircraft engine AI-25 including its deflections of its casing, Report of Granted Research GAČR No. 102/96/0183, TU and MA Brno (in Czech).

Malenovský, E. and Zapoměl, J. (1994) The investigation of asymmetric rotors dynamic properties, International Conference on Numerical Methods in Continuum Mechanics, High Tatras, Slovakia, pp. 187-193.

Vance, J.M. (1990) Rotordynamics of Turbomachinery, Wiley, New York.

Zapoměl, J. and Malenovský, E. (1993) The modelling of rotors systems behaviour using FEDYNA computer package, International Conference, TU Ostrava.

Zapoměl, J. and Malenovský, E. (1994) Approaches to the analysis of the stability of rotor transversal vibrations. International Conference, TU Ostrava.

Zapoměl, J. and Malenovský, E. (1996) Computer modelling of nonlinear behaviour of rotors with fluid - film bearings. EUROMECH - 2nd European Nonlinear Oscillation Conference, Prague, pp. 507-510. 


\section{ait \\ ENERGY MATERIALS}

M A N E Y publishing

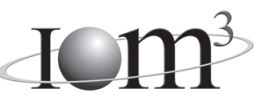

\section{Materials Science \& Engineering for Energy Systems}

Maney Publishing on behalf of the Institute of Materials, Minerals and Mining

The Institute of Materials, Minerals \& Mining

Economic and environmental factors are creating ever greater pressures for the efficient generation, transmission and use of energy. Materials developments are crucial to progress in all these areas: to innovation in design; to extending lifetime and maintenance intervals; and to successful operation in more demanding environments. Drawing together the broad community with interests in these areas, Energy Materials addresses materials needs in future energy generation, transmission, utilisation, conservation and storage. The journal covers thermal generation and gas turbines; renewable power (wind, wave, tidal, hydro, solar and geothermal); fuel cells (low and high temperature); materials issues relevant to biomass and biotechnology; nuclear power generation (fission and fusion); hydrogen generation and storage in the context of the 'hydrogen economy'; and the transmission and storage of the energy produced.

As well as publishing high-quality peer-reviewed research, Energy Materials promotes discussion of issues common to all sectors, through commissioned reviews and commentaries. The journal includes coverage of energy economics and policy, and broader social issues, since the political and legislative context influence research and investment decisions.

\section{CALL FOR PAPERS}

Contributions to the journal should be submitted online at http://ema.edmgr.com

To view the Notes for Contributors please visit: www.maney.co.uk/journals/notes/ema

Upon publication in 2006, this journal will be available via the Ingenta Connect journals service. To view free sample content online visit: www.ingentaconnect.com/content/maney

For further information please contact:

Maney Publishing UK

Tel: +44 (0)113 2497481 Fax: +44 (0)1132486983 Email: subscriptions@maney.co.uk

or

Maney Publishing North America

Tel (toll free): 8662975154 Fax: 6173546875 Email: maney@maneyusa.com

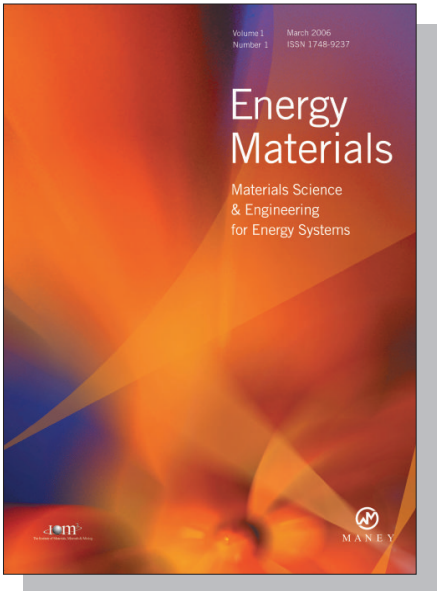

EDITORS

Dr Fujio Abe

NIMS, Japan

Dr John Hald, IPL-MPT, Technical University of Denmark, Denmark

Dr R Viswanathan, EPRI, USA

\section{SUBSCRIPTION INFORMATION}

Volume 1 (2006), 4 issues per year

Print ISSN: 1748-9237 Online ISSN: 1748-9245

Individual rate: $£ 76.00 / U S \$ 141.00$

Institutional rate: $£ 235.00 /$ US $\$ 435.00$

Online-only institutional rate: $£ 199.00 / U S \$ 367.00$

For special $\mathrm{IOM}^{3}$ member rates please email

subscriptions@maney.co.uk

\section{For further information or to subscribe online please visit www.maney.co.uk}



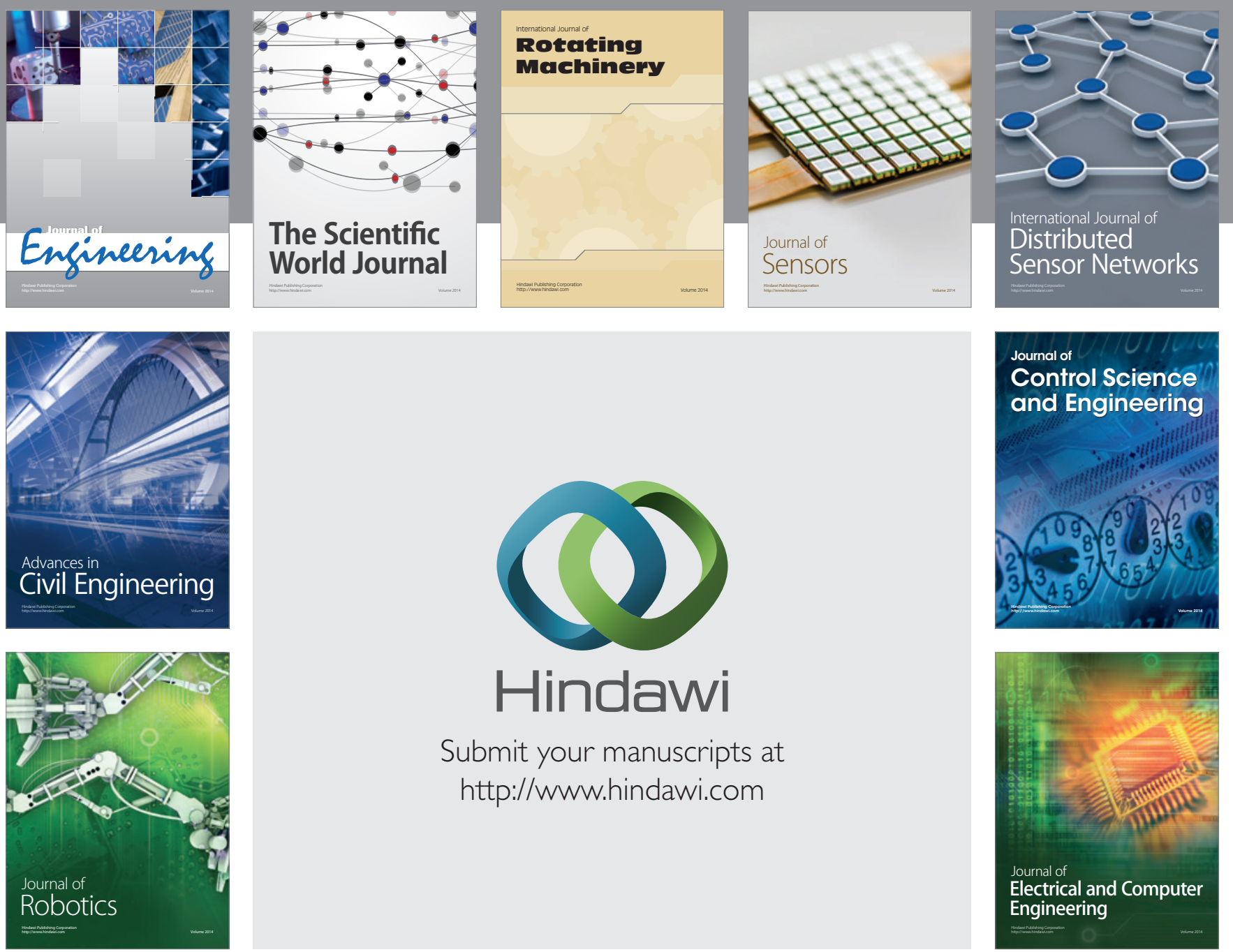

Submit your manuscripts at

http://www.hindawi.com
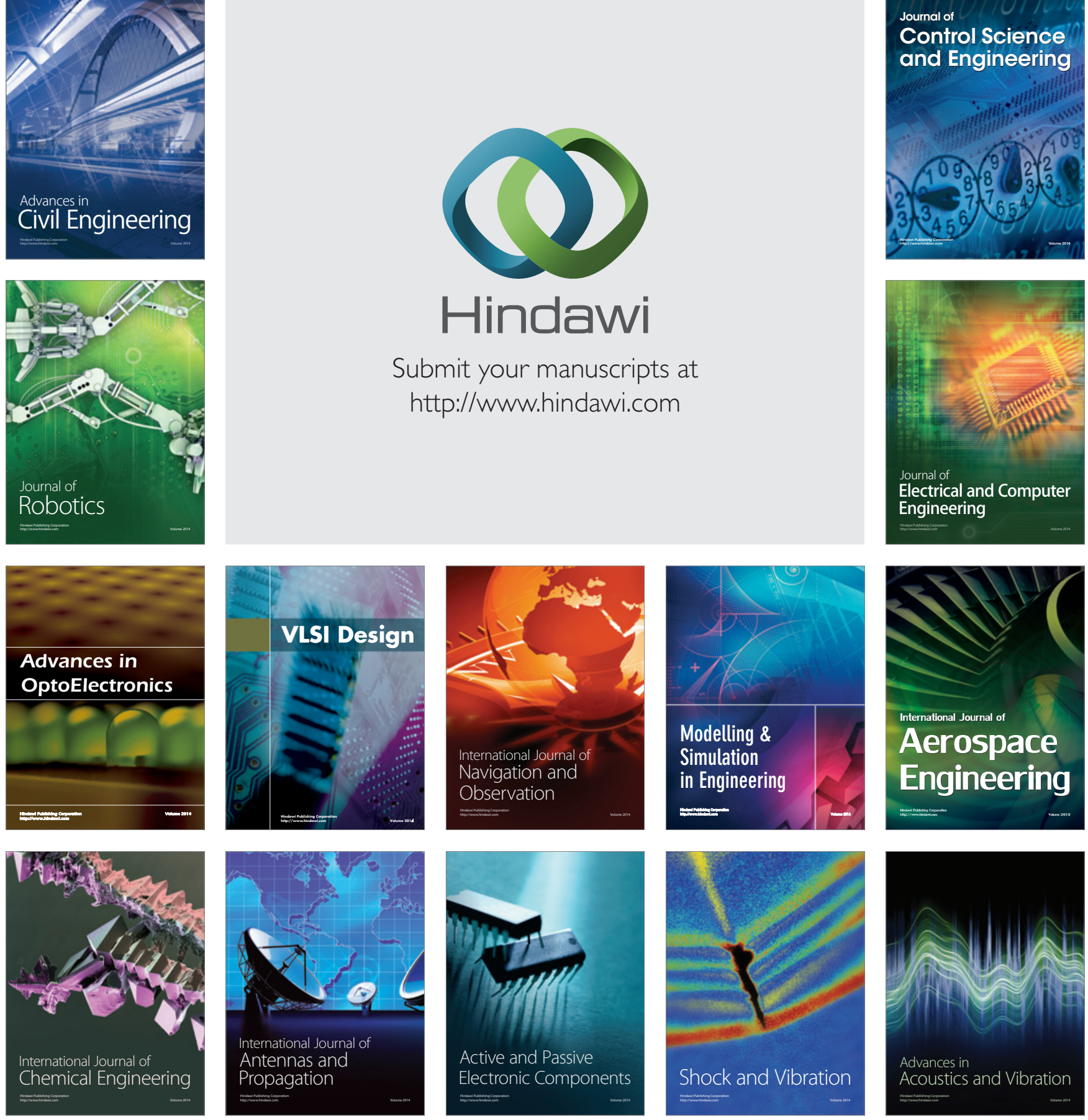